\title{
Supply Chain Management as a Competitive Advantage of Fast Moving Consumer Goods SMEs in South Africa
}

\author{
Kenneth Mathu \\ Department of Transport Economics and Logistics Management, School of Economic Sciences, Faculty of Economic and Management \\ Sciences, North West University, Mahikeng, South Africa
}

Email address:

kenmathu@yahoo.com, Ken.Mathu@nwu.ac.za

To cite this article:

Kenneth Mathu. Supply Chain Management as a Competitive Advantage of Fast Moving Consumer Goods SMEs in South Africa. Journal of Energy and Natural Resources. Vol. 10, No. 1, 2021, pp. 33-38. doi: 10.11648/j.jenr.20211001.14

Received: February 15, 2021; Accepted: March 8, 2021; Published: March 17, 2021

\begin{abstract}
The supply chain management strategy adoption by enterprises in the last four decades, has made enterprises more customer-centric, as they focus on product flow from source to the ultimate end-user. Consequently, the phrase 'customer is king' has become synonymous with good customer service. The study explored the coordinated supply chain processes as a competitive advantage for the South African small and medium-sized enterprises (SMEs) of fast moving consumer goods (FMCGs). The study was grounded in the theory of competitive advantage and qualitative research methodology and constructivism research paradigm were used. The SMEs from Gauteng province, which is the South Africa's leading economic hub provided the sample for the study. Non-probability sampling was used in selecting the participants of the study who were the owner/managers of the SMEs. The interview covered enterprise relationship with suppliers of fast moving consumer goods (FMCGs) and third-party logistics (3PL) transportation service. The recorded interviews were transcribed, translated, coded and analysed via content analysis to determine the outcome of the study. The results indicated that SCM improved cost-effectiveness through savings on 3PL transportation service optimisation shared amongst the SMEs, and improved customer service, through enhanced supplier-customer relationship that maintained continuous flow of products/services.
\end{abstract}

Keywords: Competitive Advantage, FMCGs, Grocery SMEs, SCM, 3PL

\section{Introduction}

The adoption of supply chain management (SCM) in the last four decades has enhanced competitiveness of firms including small and medium-sized enterprises (SMEs). The enhancement of supplier/customer information sharing speeded-up product flow through the distribution channels to the end-customers, providing competitiveness to enterprises [15]. An exploration of supply chain management as a competitive advantage of the SMEs trading in grocery and apparel in South Africa was conducted in Gauteng province, which is the leading economic hub in the country [23]. The supply chain networks of the selected SMEs were reviewed from the suppliers through distribution channels comprising of grocery and apparel stores, and the 3PL transportation service providers.

Some of the factors that led to competitive advantage of enterprises comprised ability to differentiate from the competitor's products, and operating at the lowest cost with higher margin [2]. Other factors included supplier-customer collaboration, enhanced SCM activities such as procurement, production, sales forecasting and delivery of end-products [28].

The supplier-customer relationship and enhanced information flow through electronic data interchange (EDI) and internet build a collaborative relationship that is beneficial to the supply chain partners [25]. Logistics management which is a component of SCM ensures that materials and products are delivered timeously, at the right place, at the required quantity and at the right cost [1]. The third-party logistics (3PL) companies that provide transportation or transportation and warehousing services are preferred for reliability and cost-saving in the supply chain [19].

The study pursed qualitative research methodology and constructivism paradigm in the exploration process. The 
study was underpinned in Porter's theory of competitive advantage.

\section{Theoretical Framework}

The study was grounded in the theory of competitive advantage which preceded enterprises' competitiveness [21]. The competitive advantage theory emphasised on cost leadership and differentiation. Some of the traits of cost leadership include "high efficiency and capacity utilisation, low-cost base use of bargaining power to negotiate production costs and access to distribution channels". The improved performance areas are the basis of value creation for customers, while differentiation in an organisation include "research, development and innovation, superior product quality, recognisable branding and distribution channels" [11].

The fast moving consumer goods SMEs in South Africa practiced both cost and differentiation traits of competitive advantage theory, as they pooled together the transportation service to save cost and enhanced customer service through continuous product availability to the end-customers [6].

\section{Literature Review}

The literature focused on the role of SCM of fast moving consumer goods SMEs in Gauteng province, South Africa, FMCGs suppliers of grocery and apparel and the third-party logistics (3PL) transportation service providers. The use of technology is ultimate for successful supply chains [27]. Hence, the use of technology in the South African SMEs was expressed, mainly the computers and smart phones for the provision of internet connectivity for placing orders and the computes for inventory control [20]. The SMEs in South Africa are categorised as businesses that has a turnover of about ZAR 64 million per annum [18].

\subsection{Supply Chain Management (SCM)}

The Council of Supply Chain Management Professionals (CSCMP) provided a fitting definition that states: "Supply chain management encompasses the planning and management of all activities involved in sourcing and procurement, conversion and all logistics management activities. It also includes coordination and collaboration with channel planners, which can be suppliers, intermediaries, third-party service providers and customers. In essence, supply chain management integrates supply and demand management within and across companies" [19]. Supply chain is a "network of businesses that participate through the linkages of both upstream and downstream in distinct business processes and activities used to create value in the form of products and services for the end-customer" [4].

As competition increases among retailers, the supply chain optimisation is enhanced, increasing value for the customers/consumers [5]. The core functions of supply chain include operations, sales/marketing, order processing, transportation, distribution, inventory and materials management, finance, and customer service. These functions constitute supply chain network from supply side through operations or manufacturing to the demand side [17]. The supply chain network of grocery SMEs in South Africa is in three levels that comprise the FMCGs and wholesaler suppliers; 3PL transportation providers; and the grocery SMEs as the customers.

\subsection{Logistics Management}

Logistics management is a leading component of SCM concerned with transportation and warehousing functions. The CSCMP defined of logistics management as "that part of supply chain management that plans, implements, and controls the efficient, effective forward and reverse flow and storage of goods, services and related information between the point of origin and the point of consumption in order to meet customers" requirements". The definition is also summarised as "the management of inventory, at rest or in motion" [26]. The South African manufacturers/suppliers are geographically scattered and far from customers, rendering supply chain process complex and expensive, which require innovative strategies to build competitiveness and increase profit [12].

\subsection{Reverse Logistics}

Reverse logistics comprise that "part of returns management that plans, implements and controls the efficient, effective flow of goods and related information from a point of consumption back to a point origin in order to recapture value or properly dispose of the goods" [19]. These are returns to the suppliers from the customers/consumers for the purpose of replacement or refurbishment for resale. Reverse logistics which is also referred as "return management" is the backward flow of goods from customers in the supply chain occurring when goods are returned by the end-consumer or by business customer within the supply chain [28]. In managing product returns, an enterprise creates value by saving on possible wastage, which is a competitive advantage [24]. Businesses can achieve competitive advantage through improved operational performance in SCM and financial management [30].

The South African FMCGs retailers operate in low margin business environment and value recovery from reverse logistics is a deserved opportunity.

\subsection{Fast Moving Consumer Goods Suppliers}

Fast moving consumer goods (FMGs) are relatively low priced goods with very short shelf-life and are purchased frequently on daily basis by customers [16]. These low-cost consumer goods include perishable and processed food products, over-the-counter medications and frequently purchased low-priced apparels and electronics components among others. In South Africa, the suppliers of processed products are food and beverage companies, healthcare and personal care product firms and suppliers of perishables such as vegetables, dairy, poultry and beef products among others 
[3].

The grocery SMEs provide one of the leading distribution channels of FMCGs [14]. Utilisation of third-party logistics (3PL) saves cost for enterprises [8]. A generic supply chain comprises of suppliers, manufacturers, distributors, retailers, and customers [1]. This study looked at the supply chain from the FMCG manufacturers or suppliers of finished products to the customer (grocery and apparel SMEs) to the consumers.

\subsection{Third-Party Logistics Firms}

The third-party logistics (3PL) firms deliver the right product at the right time at the right place at the right price [13]. The comprehensive services provided by 3PL include transportation, warehousing, cross-docking, inventory management, packaging and freight forwarding [4].

Transportation: the crucial movement of products/goods from the supplier to the customers.

Warehousing: receiving, safe-keeping, sorting of products, order preparations and dispatching orders to the customers among other functions.

Cross-docking: providing facility to receive goods and dispatch straight away to the customers without having to be stored in the warehouse.

Inventory management: stock management of the products in the warehouse.

Packaging: repacking bulk orders into small quantities as per order requirements.

Freight forwarding: coordination and shipment of products through the required mode of transportation.

The 3PL provide quality transportation management and process improvement. Some of the important functions of the 3PL firms include provisions of product visibility, creating low cost network and establishing reliable transit time [1]. These services are key to the success of the SMEs in South Africa.

\subsection{Supply Chain Collaboration (SCC)}

Supply chain collaboration (SCC) involves two or more independent enterprises working together, planning and executing the operations of supply chain management. The SCC happens at three levels: transaction integration, information-sharing and joint planning (strategic collaboration) [25].

Transaction integration: It is concerned with the process of procurement - buying, invoicing, payment and other related functions.

Information-sharing: It involves sharing of production, bill of materials and service levels among others.

Joint planning (strategic collaboration): It is concerned with the long-term supply chain cooperation (collaboration) that enhances efficiency and effectiveness of the operations.

The three levels of collaboration are applicable in all enterprises including the grocery SMEs in South Africa, as the practice render enterprises more competitive and sustainable. The optimisation of procurement and delivery services are some of the core functions of enterprises [13].

\subsection{Competitive Advantage}

Competitive advantage is "a firm's ability to produce a good or service more efficiently than its competitors, which lead to a greater profit margin, creating a competitive advantage" [21]. Porter provided four sources of competitive advantage that can be summarised in two core areas of cost leadership and differentiation. This explains the Porter's five forces model for SMEs marketing plan to enable them withstand competition. The five forces are: "competitive rivalry; threat of substitute products; bargaining power of buyers; threat of new entrants and bargaining power of suppliers" [29]. To withstand the threats posed by these forces, the South African grocery SMEs focus on saving on transportation optimisation which is the major cost driver of the business. Both forward and reverse flow of the products are considered when the SMEs share the transportation service in pursuit of competitiveness and sustainability.

\subsection{Technology Use in Supply Chain Management}

Technology allow entities including SMEs to connect to the world's knowledge pool to create and establish opportunities for collaboration in supply chain. The suppliercustomer integration is a typical example, where the electronic data exchange (EDI) or computer network link the supplier with the customer [13]. The technology is a driver and facilitator of change that can improve efficiency and effectiveness of a supply chain. The implementation of technology requires upfront analysis and planning to solve or mitigate problems in a supply chain [7]. The other technologies used in the supply chain include, enterprise resources (ERP), warehouse management (WMS), transport management systems (TMS), barcode and radio frequency identification (RFID).

The technologies used in the South African SMEs are not sophisticated as the functions are limited to enhanced order placement via internet and that require computer network and smart phones. The computers are also used for stock control [19].

\section{Problem Statement}

The SMEs are a crucial sector of the economy of nations, including South Africa due their sizeable contribution to the growth domestic product (GDP) and as a leading employer among other socio-economic benefits [23]. Apparently, this crucial role prompted the need to explore the success of the SMEs in the national economy. Thus, the study explored supply chain management as a competitive advantage for SMEs in South Africa.

\subsection{Primary Objective}

The primary objective of the study explored supply chain management application in the South African grocery SMEs 
as a competitive advantage.

\subsection{Empirical Objectives}

Three empirical objectives were pursued as follows:

1. Exploring supply chain collaboration as an enabler of constant flow of products for continuous operations.

2. Exploring cost saving from transport optimisation accrued from shared 3PL transportation service by the SMEs.

3. Exploring that reverse logistics recovered value and reduced waste.

\section{Methodology and Design}

The qualitative research methodology and constructivism research paradigm were pursued in the exploration of supply chain management application as a competitive advantage for the SMEs in South Africa. Constructivism like qualitative research is the process through which interviews are conducted with participants to generate research data [10].

Research design is the framework of a study for generating empirical evidence to examine the research questions [22]. The empirical evidence of the study was derived from the data collected from the participants in the study, who were the owner/managers of grocer SMEs in Gauteng province of South Africa. The interviews were conducted telephonically due to the prevailing lockdown regulations to maintain social distancing in the country, in compliance with the Coronavirus pandemic regulations.

The study was grounded in the Porter's theory of competitive advantage which emphasis on cost leadership and differentiation. A sample size of 16 SMEs comprising of eight grocery and 8 apparel stores were identified, and nonprobability sampling process used. The participants were introduced to the study via e-mail and telephone, and they were assured of "confidentiality and non-disclosure, as posited in research methodology [9]". They were informed of the interview duration of 10-15 minutes and that it was to be recorded with a digital voice recorder to allow for data analysis.

The recorded interviews were eventually transcribed, interpreted, coded and analysed via content analysis as prescribed in research methods [22]. The emerging views from the participants were expressed as major themes and sub-themes, which provided the outcome of the study.

\section{Results and Discussions}

The analysis of the transcribed data revealed six major themes and several sub-themes which supported the outcome of the study. The major themes comprised of transport optimisation, supplier-customer relationship, 3PL, products replacement, technology use and information sharing. The prominent sub-themes were transportation cost, own transport, use of smaller trucks, sharing transport, overstocking, damaged products and smart phones among others. The themes concurred with the views expressed by the participants and resonated with the primary and empirical objectives of the study. The technology in form of internet connectivity enhanced information flow and improved the supply chain collaboration between the FMCGs and 3PL suppliers and the grocery SMEs.

The three empirical objectives set for the study were achieved as stated:

\subsection{Empirical Objective 1: "Exploring Supply Chain Collaboration as an Enabler of Constant Flow of Products for Continuous Operations"}

The supplier-customer relationship was found to be key for the SMEs as it enabled timeous coordination of orders and transportation of goods by the 3PL providers. Small business requires constant supply of inventories to remain competitive, as they possess limited storage facilities. Thus, the relationship with the FMCGs and 3PL suppliers is crucial to facilitate continuous operations. This is confirmed by the remarks of participant 7:

"We try to establish good working relationship with manufacturers and wholesalers who are our suppliers. As the delivery costs are very high, small businesses in our region share outsourced transportation to reduce cost. Transportation is one of the major cost in our business and we try to control it to reduce costs"

\subsection{Empirical Objective 2: "Exploring Cost Saving from Transport Optimisation Accrued from Shared $3 P L$ Transportation Service by the SMEs"}

One of the leading cost components of small and mediumsized enterprises is transportation. Traditionally. Enterprises had used own or hired transportation, but the cost still remained high. With the advent of SCM, SMEs has refocused on sharing transportation to reduce cost. SMEs in a given geographical location share 3PL logistics firms to utilise fullload transportation, which has cost reduction benefit. This optimised mode of transportation increases the SMEs profitability and makes them more competitive.

Participant 12 remarked:

"Transportation cost kills our business. Three 3PL firms in our area approached us to share transportation with other businesses and increase delivery frequencies which would also reduce cost. At first it sounded unique, but over tin years now we haven't looked back. We receive supplies on the second day after placing orders as opposed to weekly and longer in the past".

\subsection{Empirical Objective 3: "Exploring That Reverse Logistics Recovered Value and Reduced Waste"}

Reverse logistics is crucial for all businesses for recovering value from damaged and returned products. The process also benefits the environment, as the refurbished products are not dumped in the landfill as waste. Thus, creating value from damaged products and 
reducing waste to the environment. As pertains to SMEs, value recovery is crucial, as these enterprises operate in a low margin environment. The recovered value adds to the profitability of the enterprises which is a competitive advantage.

The participants 2 emphasised on the benefits of receiving compensation in form of products for resale or cash in lieu as follows:

"The shared transportation is also used to return the damaged goods and wrong orders received for replacement or refurbishing. We receive cash compensation or products for resale. This helps to reduce loses and we have reduced load to take to the landfills. We also recover value from packaging materials that we sell at minimal cost to the recyclers".

\section{Conclusion}

The study explored the SCM application as a competitive advantage in the South African fast moving consumer goods SMEs. The qualitative research methodology and constructivism research paradigm were pursued. Porter's theory of competitive advantage which emphasises on cost leadership and differentiation underpinned the study. The supplier-customer relationship between the SMEs and the product and transportation suppliers who were the FMCGs and 3PL firms was extensively covered to establish the empirical objectives set for the study.

The grocery SMEs in Gauteng province formed the sample of the study and an in-depth exploration of SCM was conducted covering the components of logistics management, reverse logistics, 3PL, supply chain collaboration, and the use of technology. Under the prevailing Coronavirus pandemic, the interviews were conducted telephonically with the owner/managers of the SMEs and recorded with a voice recorder. The recoded data was then transcribed, translated, coded and analysed via content analysis to establish the outcome of the study. Six major themes and a number of subthemes emerged from the study and their interpretation indicated that the three empirical objectives set were established.

\section{Managerial Implications}

The study explored the application of supply chain management strategy in grocery SMEs in South Africa. The logistics management and reverse logistics which are components of SCM responsible for the management of the forward and backward flow of products, reflected management complexity involved. The theory of competitive advantage that underpinned the study stipulated how competitiveness was achieved through management of cost and differentiation of the products marketed. Other management implications were managing supplier-customer relationship through supply chain collaboration and managing the information and product flow using technology.

\section{Recommendations}

This study explored only the first moving consumer goods SMEs to establish how the application of SCM turned to be a competitive advantage. A future study is recommended to include the top-end retailers to provide a holistic level of the competitiveness achieved from the application of SCM in a wider range of enterprises. A mixed method would be preferred to try and narrow the gap in the outcome of the study.

\section{References}

[1] APICS Dictionary. 2013. Supply Chain Dictionary. $14^{\text {th }}$ ed. Chicago, IL: APICS Publishing.

[2] BALDWIN, M. D. 2014. Strategy: Low cost or differentiation. [Online]. Available at: https://www.cssp.com/strategy-low-cost-or-differentiation/. Accessed on 2021-02-13.

[3] BIZ CCOMMUNITY. 2020. Distribution companies South Africa. [Online]. Available at: https://www.bizcommunity.com/Companies/196/553.html. Accessed on 2020-11-27.

[4] CHRISTOPHER, M. 2016. Logistics and Supply Chain Management. $5^{\text {th }}$ ed. Harlow, UK: Pearson Education.

[5] CIRILlO, V. 2020. Supply chain increases the competitiveness of your company: Technologies and strategies. [Online]. Available at: https://www.business2community.com/strategy/supply-chainincrease-the-competitiveness-of-your-company-technologiesand-strategies-02348056. Accessed on 2021-02-12.

[6] EICKER, T. \& CILLIERS, J. O. 2017. Equipping small business retailers to manage logistical supply chain drivers: A theoretical guideline. [Online]. Available at: https://doi.org/10.4102/jtscm.v1 1i0.332. Accessed on 202102-13.

[7] GHADGE, A., WEIB, M., CALDWELL, D. \& WILDING, R. 2019. Managing cyber risk in supply chains: A review and research agenda. Supply Chain Management: An International Journal. [Online]. Available at: DOI: 10.2139/ssm.3426030. Accessed on 2021-02-06.

[8] KANBAN LOGISTICS. 2019. 7 Ways 3PLs can reduce your logistics costs. [Online]. Available at: https://www.kanbanlogistics.com/7-ways-3pls-reducelogistics-costs/. Accessed on 2020-11-26.

[9] KUMAR, R. 2016. Research Methodology: A Step-by-Step Guide for Beginners. London, UK: Sage.

[10] LEE, N. \& LINGS, I. 2008. Doing Business Research: A Guide to Theory and Practice. London, UK: Sage.

[11] LEE K. \& YOO, J. 2019. How does open innovation lead competitive advantage? A dynamic capability view perspective. Plos One Journal. https://doi.org/10.1371/journal.pone.0223405.g001.

[12] LEO, B. 2018. How to access Africa's booming FMCG opportunities. [Online]. https://www.bizcommunity.africa/Article/410/162/178892.htm 1. Accessed on 2021-02-12. 
[13] MANGAN, L., LALWANI, C., BUTCHER, T. \& JAVADPOUR, R. 2012. Global Logistics \& Supply Chain Management. $2^{\text {nd }}$ ed. West Sussex, UK: John Willey.

[14] MARIE, R. 2019. How do FMCG companies increase sales in Africa? [Online]. Available at: https://supplychain.enchange.com/how-do-fmcg-companiesincrease-sales-volume-in-africa. Accessed on 2020-11-26.

[15] MATHU, K. M. 2019. The information technology role in supplier-customer information-sharing in the supply chain management of South African small and medium-sized enterprises. South African Journal of Economic and Management Sciences 22 (1). Available at: http://dx.doi.org/10.4102/sajems.v22i1.2256. Accessed on 2021-02-06.

[16] MCKINSEY \& COMPANY. 2018. The new model of consumer goods. [Online]. Available at: https://www.mckinsey.com/industries/consumer-packagedgoods/our-insights/the-new-model-for-consumer-goods. Accessed on 2021-02-13.

[17] NAGURNEY, A., CRUZ, J., DONG, J. \& ZHANG, D. 2005. Supply chain networks, electronic commerce and supply side and demand side risk. European Journal of Operational Research, 1 (164): 120-142.

[18] OECD. 2020. Key facts on SME financing in South Africa. [Online]. Available at: https://www.oecdilibrary.org/sites/37b75ad0en/index.html?ite $\mathrm{mId}=/$ content/component/37b75ad0-en. Accessed on 2021-0206.

[19] PIENAAR, W. J. \& VOGT, J. J. Business Logistics Management: A Value Chain Perspective. Cape Town: Oxford University Press.

[20] PIN, W. S. P. 2019. Five essential technologies for inventory control in warehouse contract. [Online]. Available at: https://sipmm.edu.sg/five-essential-technologies-inventorycontrol-warehouse-contract/. Accessed on 2021-02-6.

[21] PORTER, M. E. 1995. The Competitive Advantage: New
York, NY: Free Press. [Online]. Available at: https://www.ifm.eng.cam.ac.uk/research/dstools/portersgeneric-competitive-strategies/. Accessed on 2020-11-08.

[22] SAUNDERS, M. N. K., LEWIS, P. \& THORNHILL, A. 2020. Research Methods for Business Students. $8^{\text {th }}$ ed. Birmingham, UK: Pearson Education.

[23] STATISTICS SOUTH AFRICA. 2019. Four facts about provincial economies. [Online]. Available at: http://www.statssa.gov.za/?p=12056. Accessed on 2021-01-08.

[24] STOCK, J. R. 2006. Managing product returns for competitive advantage. MIT Sloan Management Review, 48 (1): 57-62.

[25] SUNDARAVARADAN, S. 2020. Levels and types of collaboration across the supply chain. [Online]. Available at: https://blogs.sap.com/2020/01/28/levels-and-types-ofcollaboration-across-the-supply-chain/. Accessed on 2021-0213 .

[26] STROL, M. B. 2002. What is logistics. [Online]. Available at: http://www.logisticsnetwork.net/articles/What\%20is\%20Logis tics.pdf. Accessed on 2021-02-06.

[27] UKEssays. 2020. The role of technology in supply chains. [Online]. Available at: https://www.ukessays.com/essays/management/the-role-oftechnology-in-supply-chains.php. Accessed on 2020-11-28.

[28] WISNER, J. D., TAN, K-C. \& LEONG, G. K. 2016. Principles of Supply Chain Management: A Balanced Approach. $4^{\text {th }}$.ed. Boston, MA: Cengage Learning.

[29] WRIGHT, G. 2020. How to apply Porter's 5 Forces model to your SME marketing plan. [Online]. Available at: https://www.smartinsights.com/online-brand-strategy/branddevelopment/how-to-use-porters-5-forces-model/. Accessed on 2021-02-13.

[30] ZANOTTI, C., REYES, F. \& FERNANDEZ, B. 2017. Relationship between competitiveness and operational and financial performance of firms: An exploratory study on European brewing industry. Omnia Science. Available at: https://doi.org/10.3926/ic.1104. Accessed on 2021-02-13. 